\title{
P017. Ictal cutaneous allodynia does not affect pain perception in patients with migraine: a trigeminal heat stimulation study during interictal period
}

\author{
Antonio Russo ${ }^{1,2,3^{*}}$, Francesca Conte ${ }^{1}$, Laura Marcuccio ${ }^{1}$, Alfonso Giordano ${ }^{1,2}$, Gioacchino Tedeschi ${ }^{1,2,3}$, \\ Alessandro Tessitore ${ }^{1}$
}

From Abstracts from the 1st Joint ANIRCEF-SISC Congress

Rome, Italy. 29-31 October 2015

\section{Background}

Migraine is a disabling neurological condition characterized by headache attacks, hypersensitivities to visual, auditory, olfactory and somatosensory stimuli, nausea and vomiting. Peripheral and central sensitization of trigeminovascular neurons seem to play a critical role in different aspects of migraine pathophysiology [1]. In the last years, several studies investigated pain thresholds in patients with migraine during both attacks and interictal periods. However, pain perception in patients with migraine has been poorly explored.

\section{Objective}

To investigate perception intensity of trigeminal heat stimulation (THS) [2] in patients with migraine without (MwoA CA-) and with allodynia (MwoA CA+) compared to healthy controls $(\mathrm{HC})$ and correlation with clinical parameters of migraine severity.

\section{Methods}

We enrolled 80 patients with migraine (40 patients with MwoA CA- and 40 patients with MwoA CA+) and $60 \mathrm{HC}$. THS was performed using the contact heat evoked potential stimulator (CHEPS) at three different intensities: a low-innocuous stimulus at $41^{\circ} \mathrm{C}$ and two painful heat stimuli at $51^{\circ}$ and $53^{\circ} \mathrm{C}$ (to provide a moderate-noxious and a high-noxious stimulus). Subjects had to verbally rate the intensity perception of the experimental stimulus by means of a numerical rating scale (NRS) ranging from 0 ("no pain") to 10 ("worst pain imaginable").

\footnotetext{
* Correspondence: dottor.russo@gmail.com

'Department of Medical, Surgical, Neurological, Metabolic and Aging

Sciences, Second University of Naples, Naples, Italy

Full list of author information is available at the end of the article
}

\section{Results}

NRS of pain perception was not significantly different between patients with MwoA (as a group) and $\mathrm{HC}$ at any level of experimental stimuli. The absence of significant differences in pain perception was also found between patient groups defined as patients with MwoA $\mathrm{CA}$ - and with MwoA CA+ compared to $\mathrm{HC}$, at any level of experimental stimuli.

\section{Conclusions}

In the present study, by using three predefined temperatures, we demonstrated that pain intensity ratings are not significantly different between both $\mathrm{CA}+$ and CAmigraine patients and patients with migraine as a group compared to HC. Previous studies suggested a low heat pain threshold in migraine patients during interictal period [3]. However, it is well known that the pain intensity is different from the pain threshold [4]. Furthermore, we cannot exclude that ictal CA, subtended by central sensitization of trigeminovascular neurons, may revert during interictal period without consequences on pain perception. Central sensitization could become progressively more severe over time and, by an imbalance between the inhibition and the facilitation of pain dynamics, might contribute to chronification phenomena, interictal CA and probably pain perception abnormalities.

Written informed consent to publication was obtained from the patient(s).

\footnotetext{
Authors' details

${ }^{1}$ Department of Medical, Surgical, Neurological, Metabolic and Aging Sciences, Second University of Naples, Naples, Italy. ${ }^{2}$ MRI Research Center SUN-FISM, Second University of Naples, Naples, Italy. ${ }^{3}$ Institute for Diagnosis and Care "Hermitage Capodimonte", Naples, Italy.
} 


\section{References}

1. Bernstein C, Burstein R: Sensitization of the trigeminovascular pathway: perspective and implications to migraine pathophysiology. I Clin Neurol 2012, 8(2):89-99.

2. Russo A, Tessitore A, Esposito F, Marcuccio L, Giordano A, Conforti R, Truini A, Paccone A, d'Onofrio F, Tedeschi G: Pain processing in patients with migraine: an event-related fMRI study during trigeminal nociceptive stimulation. J Neurol 2012, 259(9):1903-1912.

3. Schwedt TJ, Chiang CC, Chong CD, Dodick DW: Functional MRI of migraine. Lancet Neurol 2015, 14(1):81-91.

4. Schwedt TJ, Zuniga L, Chong CD: Low heat pain thresholds in migraineurs between attacks. Cephalalgia 2015, 35(7):593-9.

doi:10.1186/1129-2377-16-S1-A128

Cite this article as: Russo et al:: P017. Ictal cutaneous allodynia does not affect pain perception in patients with migraine: a trigeminal heat

stimulation study during interictal period. The Journal of Headache and Pain 2015 16(Suppl 1):A128.

\section{Submit your manuscript to a SpringerOpen ${ }^{\mathcal{O}}$ journal and benefit from:}

- Convenient online submission

- Rigorous peer review

- Immediate publication on acceptance

- Open access: articles freely available online

- High visibility within the field

- Retaining the copyright to your article

Submit your next manuscript at $\gg$ springeropen.com 